\title{
Human Papillomaviruses, Herpes Viruses and Oral Neoplasms
}

\section{Assya Krasteva ${ }^{1}$, Antoaneta Dobreva ${ }^{2}$, Veselin Galabov ${ }^{2}$, Anelia Gozeva $^{3}$}

1. Department of Oral and Imaging diahnostics, Faculty of Dental medicine, Medical University - Sofia, Bulgaria;

2. Dental sytdent, Faculty of Dental medicine, Medical University - Sofia, Bulgaria;

3. Military Hospital, Department of Microbiology and virology, Sofia, Bulgaria;

\begin{abstract}
Human papillomaviruses constitute the most widely spread sexually transmitted viral infection world-wide. In about $1 \%$ of the cases, a continuing HPV infection can lead to the appearance of precancerous conditions. In a subsequent carcinoma progression, different types of cancer can develop - cervical, rectal, penile, oral, throat, laryngeal, etc. More than 200 HPV types have been established, with at least 25 found in lesions in the oral cavity.

The attention of specialists in the field has been focused on the association between HPVs and oral carcinogenesis. It is highly recommended that each patient with a suspected lesion in the oral cavity should be tested for HPV.
\end{abstract}

Keywords: Human Papillomavirus, HPV, oral cavity, manifestation, oral cancer

\section{Background}

Human papillomaviruses (HPV) constitute the most widely spread sexually transmitted viral infection world-wide. It is considered that around $70 \%$ of sexually active humans are infected with HPV $(1,2,3,4,5,6)$. The changes these viruses can cause are in their majority benign. In about $1 \%$ of the cases, a continuing HPV infection can lead to the appearance of precancerous conditions. In a subsequent carcinoma progression, different types of cancer can develop - cervical, rectal, penile, oral, throat, laryngeal, etc. $(2,3,4,5,6)$. 
Morphological characteristics of HPV: the particles of the virus are about $55 \mathrm{~nm}$ in diameter, with circular dsDNA and un-enveloped icosohedral capsid (protein sheath). The HPV genome encodes a variety of viral proteins, with early genes (early $-E$ ) coding regulatory proteins, while late genes (late $-L$ ) coding capsid proteins. Two of the specific viral proteins - the oncoproteins E6 and E7 have a strongly pronounced transforming effect on the target cell. HPVs are resistant to various chemical and physical influences and their total inactivation requires thermal processing at $100^{\circ}$ for 1 hour $(2,3,4,5,6)$.

It is important to note that the heat generated during laser-surgical manipulations or electro- coagulation does not destroy the virus, what is more, it creates an aerosol cloud containing infectious viral DNA, which can infect the personnel carrying out the manipulations $(3,7)$.

HPVs are epitheliotropic. Their penetration in epithelial cells (keratinocytes) is a receptor-mediated process. For infection to develop there has to occur viral penetration in the basal epithelial cell, which is associated with disruption of the multilayered epithelium. HPVs have a proven oncogenetic potential. Certain viral types are characterized with low risk of carcinoma progression (HPV-6, 11), while others display high risk (HPV-16, 18, 31, 45 and some others). The basic loci for clinical developments of infections caused by HPVs are the skin, semi-mucosa and mucosa. The sexually transmitted types affect predominantly the genitals and the oral mucosa. Oral-anogenital contact is a major pathway for the transmission of HPVs in the oral cavity $(1,6,8)$. Some conditions and behaviours, which change anti-tumor immunity, can be essential for the transformation of an HPV oral infection into HPV-related malignancies (7). Most HPV-associated infections are transitory $(1,2,6)$.

Table 1. Benign and malignant papilloma lesions are the most frequently established types of papillomaviruses - HPVs (according to Z. Zlatkov)

\begin{tabular}{|c|c|c|}
\hline Papiloma lesions & Localization & HPV Types \\
\hline Verruca plantaris & Feet & $1,2,4$ \\
\hline $\begin{array}{l}\text { Verruca genitalis } \\
\text { (Condyloma acuminata) }\end{array}$ & Anogenital region & $6,11,16,18,30-32,2,43-45$ \\
\hline Papillomatosis bowenoides & Anogenital region & $16,18,31,32,35,42,51-54$ \\
\hline Morbus Bowen & Torso, genitalia & 34,48 \\
\hline Dysplasia coli uteri & Cervix & $16,18,31,32,35,42,51-54$ \\
\hline Carcinoma coli uteri & Cervix & $16,18,31,32,33,35,39,41,51-54$ \\
\hline $\begin{array}{l}\text { Epidermo dysplasia } \\
\text { verruciformis }\end{array}$ & Face, limbs, torso & $5,8,9,12,14,15,17,19-25,36-38$ \\
\hline Kerato acanthoma & Face, limbs & 9,37 \\
\hline Papilloma laryngis & Laryngeal mucosa & $6,11,55$ \\
\hline Carcinoma laryngis & Larynx & 30 \\
\hline Veruca vulgaris & $\begin{array}{l}\text { Limbs, lips and } \\
\text { corners of the mouth }\end{array}$ & $7,26-29$ \\
\hline Verruca plana & Face, limbs & $3,10,26-29$ \\
\hline
\end{tabular}

HPVs cause productive inflammations exclusively in the keratinocytes of the skin and mucosa.

In immunologically compromised patients dysplasia of the epidermis can develop, resembling a wart (Epidermodysplasia verruciformis). The virus triggers hyper production of keratin by the epidermis of the skin, which presents clinically in formations resembling warts or skin "horns".

More than $200 \mathrm{HPV}$ types have been established, with at least 25 found in lesions in the oral cavity $(9,10,11,12,13,14,15,16,17,18,19,20,21,22)$.

The attention of specialists in the field has been focused on the association between HPVs and oral carcinogenesis $(14,22,23,24,25,26,27,28)$. 


\section{Lesions in the maxillofacial area, associated with HPVs}

The most frequent benign and malignant papilloma lesions in the maxillofacial area, associated with HPVs are presented in the table below:

Table 2. HPV associated benign and malignant papilloma lesions in the maxillofacial area

\begin{tabular}{|l|c|}
\hline Papilloma lesions & HPV Types \\
\hline Oral papilloma & $6,7,11,16$ and 32. \\
\hline Warts (Vercuca vulgaris) & $1,2,3,4,26,27,28,29,38,41,49,63,65$. \\
\hline $\begin{array}{l}\text { Disseminated oral papillomatosis } \\
\text { (Papillomatosis oralis disseminata) }\end{array}$ & $6,11,16$ \\
\hline $\begin{array}{l}\text { Focal epithelial hyperplasia } \\
\text { (Heck's disease) } \\
\text { (Hyperplasia epithelialis focalis) }\end{array}$ & $13,32,16,18$ \\
\hline $\begin{array}{l}\text { Acute warts } \\
\text { (Condyloma cuminat ) }\end{array}$ & $6,10,11$ \\
\hline $\begin{array}{l}\text { Wart-like cancer } \\
\text { (Verrucous carcinoma) }\end{array}$ & 11,16 \\
\hline \multicolumn{1}{c|}{ ead and neck squamous-cell carcinoma (HNSCC) } & $6,11,16,18,31,33,35$ \\
\hline
\end{tabular}

HPVs attack squamoss epithelial cells. Unlike many other viruses, which infect the oral epithelium and destroy the cells, HPVs permeate and induce proliferative changes in these cells with subsequent cell transformations and the development of benign and malignant tumors.

Loci of predilection of oral presentations, according to clinical manifestations of HPVs:

- Oral papilloma - tongue, palate, labial and buccal mucosa

- Wart - buccal mucosa, lips and corners of the mouth

- Acute warts - oral mucosa, tongue, gingiva, buccal mucosa and soft palate

- Disseminated oral papillomatosis - lips, buccal mucosa, tongue, uvula, palate, tonsils and pharynx

- Focal epithelial hyperplasia (Heck's disease) - oral mucosa and face

- Wart-like cancer (Verrucous carcinoma) - oral mucosa

- Squamoss cell carcinomas - oral and laryngeal mucosa

The oral papilloma is an exophytic growth, with clear borders, usually attached to a stool (like a mushroom), of pale pink colour - when there is no keratinization - or of white-grayish colour with a smooth surface, looking like cauliflower. When keratinization occurs, the surface is uneven, fine- or coarse-grained, sometimes ciliated. It is soft-elastic in texture varying from 0,5 to $1 \mathrm{~cm}$ in diameter. There could be a single formation or multiple formations $(9,29)$.

Common warts usually present individually. They are small, well-formed exophytic growths with a macerated, white-grayish surface. When appearing on the vermilion border they are most frequently positioned on a wide base, and sometimes they are filiform $(9,29,30)$.

Acute warts - benign lesions, sexually transmitted, usually affecting the anogenital region and more rarely the oral cavity. Oral presentations are exophytic growths with clear borders, looking like cauliflower, with 
whitish or normal colour. They usually vary in size from 0,5 to $1 \mathrm{~cm}$. They can be single or multiple nodules. They recur frequently (9).

Disseminated oral papillomatosis - the infection can inoculate in the oral cavity from warts on the skin of the face or the fingers (especially after an attempt for removal by biting) or from another person, and also indirectly via infected objects. Viral acanthuses are multiple - up to a hundred small whitish papillomatous nodules (9).

Focal epithelial hyperplasia (Heck's disease) - the wart-like tumors on the oral mucosa are accompanied by tumors on the face.

Papillomaviruses are detected in epithelial cells via electronic microscopes, and it is generally assumed that these virulent units should be considered a form of disseminated oral papillomatosis with skin manifestations $(9,12,13,31)$.

Wart-like (verrucous) cancer - slowly growing and strongly differentiated tumor. Metastases rarely occur and it is characterised with a fairly good prognosis. It manifests in the oral cavity as an exophytic, whitish tumor growth with a papillary or verrucous surface $(9,29)$.

\section{Review Results}

\section{HPVs and oral carcinogenesis}

Statistical data reveal that $7 \%$ of Americans aged between 14 and 69 have an oral HPV infection, with the ratio men:women presented in terms of percentage measuring $10.1 \%: 3,6 \%$. Some research indicates that $72 \%$ of oral neoplasms are HPV-associated. It has been predicted that with the continuing tendency for the increased spread of these viruses, by the year 2020, HPV-associated tumors of the throat will surpass the incidence of cervical cancer as the leading HPV-induced cancers $(2,5,6,14,26,32)$.

It is highly recommended that each patient with a suspected lesion in the oral cavity should be tested for HPVs (7).

HPVs are detected with increased frequency in oral epithelium with dysplasia and with cancer in comparison to findings in cases with normal oral mucosa. Oral HPV infection, especially with high risk genotypes, has been identified as an independent risk factor for oral squamoss cell cancer (22).

Special attention should be paid to the fact that the presence of the virus in a large portion of normal, unaltered oral mucosa is a bad prognostic indicator for the possible development of malignant diseases (22). High risk HPV types have been found in cytological samples from the oral cavity (26).

HPV DNA is found in oral mucosa in $61.5 \%$ of oral cancers, $27.1 \%$ in potentially malignant lesions, $26.5 \%$ in erosive lesions of oral mucosa and $5,5 \%$ in the control group of individuals $(16,26)$.

Benign lesions in the oral region are associated with HPV 2, 4, 6, 11, 13 and 32; malignant oral lesions are associated predominantly with HPV 16 and $18(9,33,34,35)$.

\section{HPV and submucous fibrosis in the oral cavity}

HPV-16 and 18 have been found in $67 \%$ of patients with oral submucous fibrosis (18).

\section{HPV and oral lichen planus}

$31.0 \%$ of patients with lichen planus were HPV-18 positive (36). 


\section{HPV and oral leukoplakia}

Numerous studies have tried to identify HPV as a causal agent for oral leukoplakia. In 2003964 patients with leukoplakia were studied and in 31.1\% HPV-DNA was found (28). HPV types 6/11 were found in $55.8 \%$ of the cases with oral leukoplakia, followed by $27.2 \%$ proven 16/18 types (22). In another study 20 cases of leukoplakia were analysed (Lind et al., 1986), with HPV antigens found in 13 lesions, 7 of which progressed to invasive cancer in the following one year. By applying in situ hybridisation and PCR for HPV 16, researchers found such in $45 \%$ of the patients with oral leukoplakia (35). From all the analysed cases, 2 cases of erythroplakia and one case of verrucous leukoplakia progressed to invasive cancer for a period of two to four years.

\section{HPV, EBV, HSV and oral and oropharyngeal cancers}

Squamoss cell cancers in the head and neck region rank sixth among the most frequent types of cancer worldwide, with 563826 newly diagnosed cases annually (including 274850 cases of oral neoplasm, 159 363 of laryngeal neoplasm and 52100 of oropharyngeal cancers). Mean annual death rate has been calculated to 301408 (21). These facts determine their significance for human health.

Prolonged smoking and alcohol abuse have rightfully been recognized as major factors for the appearance and development of malignant diseases. In one not particularly small group of patients with cancers in the regions of the mouth and throat, no association has been established between the condition and regular smoking and drinking. An implicated cause in such cases is the presence of chronically developing oral viral infections. This hypothesis is corroborated by the fact that different quantities of viral genomes are frequently found in tumor cells. Some viruses are capable of setting on oncogenesis (HPV) on their own, while others (EBV, CMV, HSV) simply accelerate an already triggered process. Besides, different genotypes of the same virus can be highly oncogenetic (HPV-16, 18), while others are characterised with low or suspected oncogenetic potential (HPV-6, 11) $(1,30,35,37,38)$.

It is a long established fact that HPV causes cervical cancer. In recent years the number has been steadily increasing of studies trying to establish or establishing the association of this virus with squamoss-cell cancers in the faciomaxillary region. At present 15 types of HPV are considered to have pronounced oncogenetic potential (21).

HPV-associated squamoss-cell cancers of the head and neck most frequently manifest in the tongue and palatine tonsils. Once the virus infiltrates its DNA genome in the nucleus of the host cell, it transforms the expression of the oncoproteins 6 and E7. 6 protein induces the disintegration of p53 via ubiquitinmediated proteolysis, leading to a significant loss of p53 activity (21).

Papillomaviruses are classified in accordance with the level of oncogenetic risk into high (types 16, 18 and 31) and low risk (types 6,11, 42 and 36). HPV 16 is associated with 1/3 of oropharyngeal squamosscell cancers. HPV-16 and 18 are found in about $70 \%$ of cases of cervical, vaginal and anal cancers and in about 30 to $40 \%$ of cases of vulvar, penile and oropharyngeal cancers $(17,39)$. Other HPV types (HPV$31,33,45$ and some others) are also frequently found in oral mucosa (9).

It has been established that an oral HPV infection, especially with high risk genotypes, is an independent factor for oral squamoss-cell cancer (22).

A multi-center study of 1670 random patients (1415 with cancer in the oral cavity and 255 with oropharyngeal cancer) and 1732 control individuals was carried out aiming to prove the presence of an HPV (by polymerase-chain reaction) and antibodies for HPV types 16, L1, E6 and E7 proteins in the plasma (ELISA). Valid PCR biopsies (globin-positive) were obtained from 908 random patients. HPV 16 E6 / E7 serological results were valid for $93.5 \%$ of the patients and for $91.3 \%$ of the control individuals. 
Antibodies against HPV L1 were found in the plasma of $6.0 \%$ of control individuals, in $8.9 \%$ of the patients with cancer in the oral cavity and in $13.4 \%$ of the random patients suffering from oropharyngeal cancer. Antibodies against HPV E6 were found in 1.1\% of control individuals, in $2.6 \%$ of the patients with cancer in the oral cavity and in $9.9 \%$ of patients with oropharyngeal cancers (40). It is infrequently that antibodies against both HPV E6 and R7 are found in control individuals (0.1\%) and in patients with cancer in the oral cavity $(0.5 \%)$. But findings are more frequent in patients with oropharyngeal cancers (6.6\%). HPV-DNA was found in higher levels in patients with oropharyngeal cancers in phases 3 and $4(21,5 \%)$, in comparison to those in phases 0,1 and $2(7.4 \%)(40)$.

\section{Oncoviruses}

The most significant oncoviruses in oral medicine are the human papillomaviruses (HPVs) and some of the herpes viruses (EBV, HSV-1,2 и HHV-8). It has not been established whether oral tumors originate from the activation of endogenous viruses or are caused by exogenous viral infections (9).

Table 3. Virus-associated precancerous conditions and oral neoplasms (ZI. Kalvachev, 2014).

\begin{tabular}{|l|l|l|}
\hline $\begin{array}{l}\text { squamoss } \\
\text { cell cancer }\end{array}$ & $\begin{array}{l}\text { HPV } \\
\text { EBV } \\
\text { HHV-6 }\end{array}$ & $\begin{array}{l}\text { Caused by high risk HPV types (HPV-16, 18 and so on); suspected } \\
\text { association with practicing oral sex. In some forms of squamoss } \\
\text { cell cancer the presence of herpes viruses (EBV and HHV-6) has } \\
\text { been proven. The viruses are interpreted as causing agents. }\end{array}$ \\
\hline $\begin{array}{l}\text { Tonsillar } \\
\text { cancer }\end{array}$ & $\begin{array}{l}\text { HPV } \\
\text { EBV }\end{array}$ & $\begin{array}{l}\text { Usually affects one of the tonsils. DNA of one the two viruses is } \\
\text { found in tumor cells. }\end{array}$ \\
\hline
\end{tabular}

HPV-associated neoplasms of the head and neck are of exceptional clinical significance not only due to the gravity of the disease, but mostly because of its more positive prognosis for the patients, when compared to HPV-negative tumors. This is partly due to the heightened sensitivity of HPV cancers to chemotherapy and radiotherapy (21).

The future of the study of human papillomaviruses (HPVs) lies with their recognition as a compulsory screening and diagnostic component for all oropharyngeal cancers (7). 
Table 2. Comparison between HPV-positive and HPV-negative patients with squamoss cell cancers in the head and neck areas

\begin{tabular}{|c|c|c|}
\hline Morbidity: & increase & decrease \\
\hline Age: & Younger & Older \\
\hline Gender: & 3:1 men & 3:1 men \\
\hline Risk factors: & Sexual contacts & Smoking, drinking \\
\hline Co-factors: & Marijuana, immunosuppressors & Diets, oral hygiene \\
\hline $\begin{array}{l}\text { Molecular-genetic } \\
\text { findings: }\end{array}$ & P $16 \uparrow ; R b \downarrow ; P 53$ wild-type & P16 $\downarrow ;$ Rb $\uparrow ;$ P53 mutated \\
\hline Anatomical location & Lingual and palatine tonsils & All areas \\
\hline $\begin{array}{l}\text { Pathological findings: } \\
\text { 1.primary } \\
\text { 2. metastases in } \\
\text { lymphatic vessels }\end{array}$ & $\begin{array}{l}\text { Basal } \\
\text { Cystic / bubbly }\end{array}$ & $\begin{array}{l}\text { Keratinized } \\
\text { Hard/thick }\end{array}$ \\
\hline Survival rate: & Higher & Low \\
\hline
\end{tabular}

At the molecular-genetic level, HPV-positive (+) patients with squamoss-cell cancers in the head express viral oncoproteins 6 and 7, overexpress genetic products p16 and very rarely host mutated genes p53. As far as clinical behavior is concerned, HPV-16- positive patients with squamoss-cell cancers in the head and neck areas can expect a better prognosis in relation to their survival rate.

The pathological characteristics of HPV-positive (+) squamoss-cell cancers in the head and neck areas differ from the morphology of the typical non-HPV-associated squamoss-cell tumors._William H.Westra describes the following sequence in the development of the condition in HPV-positive (+) patients: 1) origination from tonsillar crypts; 2) not associated with dysplasia of the surface epithelium; 3 ) characterised by lobular growth; 4) spreading through infiltrated lymphocytes; 5) lack of significant keratinization; 6) demonstrated "basaloid" morphology (7).

\section{HPV, EBV and HSV}

Different studies search for an association between viral coinfections of the human papillomaviruses and EBV and HSV in the development of oral squamoss-cell cancers $(18,41)$.

In HIV patients, HPV, EBV and HSV are more frequently found in the oral cavity in comparison with findings in immunologically competent individuals (respectively $25.3 \%$ compared to $7.6 \%$ ). There is greater likelihood for HIV patients to be infected with more than one of the HPV genotypes $(5.8 \%$ compared to $1.5 \%$ of immunologically competent individuals) and with a genotype of high oncogenetic risk, such as HPV-16 for example, which is related to tonsillar cancers. Oral warts are rare in immunologically competent individuals, but are a regular finding in HIV patients with HPV $(25,42)$.It is appropriate and advisable to test the levels of the three viruses (HPV, EBV and HSV) in patients with HIV, as well as to monitor their specific manifestations in the oral cavity. 


\section{HPV, p16 and p53}

The established association between HPV and p16 overexpression in the transformation of oral epithelial dysplasia into squamous cell carcinoma with molecular mechanism resembles the one in cervical cancer (11).

Sanjay Katiyar and associates researched p53 codon 72 polymorphism of squamous carcinoma of the oral cavity which is associated with the HPV infection, and more specifically with HPV type 16. Altogether 44 oral carcinomas were studied. $13(29.5 \%)$ were HPV-positive (+) and 31 HPV-negative (-), with 20 healthy control individuals (43).

It is an interesting observation that the prevalence of proline instead of arginin is higher in HPV-negative $(-)$ oral carcinomas $(29 \%)$ in comparison to that in HPV-positive $(+)$ carcinomas $(7.7 \%)$ and in controls (15\%). Arginin alleles are found in a comparable per cent of HPV-negative (-) carcinomas and in controls, while in HPV-positive $(+)$ oral carcinomas the ratio is lower $(15,4 \%)$. The difference, however, is statistically insignificant: $\left(x^{2}=4.63 ; \mathrm{df} 4, \mathrm{p}=0.32\right)(43)$. Two reports from India on the frequency of $\mathrm{p53}$ codon 72 polymorphism in cases of cancer in the oral cavity also reveal low frequency of the mutation of p53. This type of cancer is associated with an HPV infection and other HPV types. Several studies suggest a suspected association between lung cancer and higher proline genotypes, instead of with arginin homozygotic genotypes. S. Katiyar and associates establish a slight prevalence of proline alleles in high risk HPV-positive (+) carcinoma in the oral cavity. The conclusion reached in the study is that the arginin genotype might be more susceptible to HPV infections and oral mucosa carcinoma (43).

\section{HPV and radiochemotherapy}

C. Lill and associates established that patients with oropharyngeal carcinoma, positive for HPV, reacted better to radiochemotherapy than patients with HPV-negative tumors (44).

\section{Diagnostic methods for human papilloma virus}

Different arrays of diagnostic methods are used for the detection of the human papillomaviruses, among which PCR, the type-specific in situ hybridisation techniques (ISH) and immunocytochemistry. Cytological and histological tests provide indirect proofs for the possible presence of an HPV-induced infection, but do not allow for typization. The effective determination of the type of HPV is achieved via molecular-biological methods, such as the most widely spread highly sensitive Polymerase Chain Reaction (PCR). DNA is extracted from the cell and the presence of specific genomic fragments characteristic of different HPV types. The preferential use of the ISH method is supported by biological and practical research findings. PCR methods have been optimized for freshly frozen samples, while ISH is an applicable and profitable test for most diagnostic labs which routinely process formalin-fixed and paraffin-embedded tissue blocks $(9,10)$.

\section{Conclusions}

Since the discovery of the human papillomavirus in 1933 by $R$. Shope to the present day, these viruses remain an area of rigorous scientific research because of their significant role in the oncogenesis of different types of cancers.

The determination of the status of HPV will undoubtedly become standard practice for the prevention of oropharyngeal carcinomas. HPV surfaces as a reliable method for the recognition of the presence and development of the disease, encompassing all aspects of the care dedicated to patients, from the early detection of the cancer and the tumor location to the choice of patients to be assigned specific therapy after a standard treatment of the tumor. 


\section{References}

1. Zlatkov Zl. Sexually transmitted diseases and non-venereal genital pathology (In Bulgarian). Publisher: Arso 2002 book.

2. Kalvachev Z. Infectious causes for the development of cancer. In Medical practice, 2008,3:6-9.

3. Kalvachev Z. Specific properties of viruses. In Clinical virology: a textbook for students of medicine, dental medicine and biology. (In Bulgarian). Publisher: Medicine and physical education 2009 book.

4. Kalvachev Z. Chronic contagious diseases. (In Bulgarian). Publisher Medicine and physical education, 2008 book.

5. Kalvachev Z, Draganov P, Simeonova M. Real-time PCR: principles and diagnostic application in virology. Sofia: Military medicine 2004;3:18-25.

6. Kalvachev Z. Human papilloma viruses. (In Bulgarian). PublisherDiagnosis Press Ltd., 2006 book.

7. Westra W. The Changing Face of Head and Neck Cancer in the 21st Century: The Impact of HPV on the Epidemiology and Pathology of Oral Cancer. Head Neck Pathol 2009,3,1,78-81.

8. Slots J. Oral viral infections of adults. Periodontology 2000 2009,49: 60-86.

9. Krasteva A, Kalvachev Z, Kisselova A. Viral infections in oral medicine. (In Bulgarian). Publisher: Medinform 2014 book.

10. Kalvachev Z. Infectious causes for the development of cancer. In Medical practice, 2008, 3: 69.

11. Angiero F, Gatta LB, Seramondi R, et al. Frequency and Role of HPV in the Progression of Epithelial Dysplasia to Oral Cancer. Anticancer Research 2010;30:9:3435-3440.

12. Bassioukas K, Danielides V, Georgiou I, et al. Oral focal epithelial hyperplasia. Eur J Dermatol 2000;10:5:395-397.

13. Beaudenon S, Praetorius F, Kremsdorf D, et al. A New Type of Human Papillomavirus Associated With Oral Focal Epithelial Hyperplasia. J Invest Dermatol 1987;88:2:130-135.

14. Elango J, Suresh $\mathrm{A}$, ErodeE, et al. Role of human papilloma virus in oral tongue squamous cell carcinoma. Asian Pac J Cancer Prev 2011;12:4:889-896.

15. Eversole LR. Papillary lesions of the oral cavity: relationship to human papillomaviruses. Journal of the California Dental Association 2000;28:12: 922-927.

16. Giovannelli L, Campisi G, Lama A, et al. Human Papillomavirus DNA in Oral Mucosal Lesions. $J$ Infect Dis 2002;185: 6:833-836.

17. Grinde B, Olsen I. The role of viruses in oral disease. Journal of Oral Microbiology 2010; 2.

18. Jalouli J, Ibrahim S, Mehrotra R, et al. Prevalence of viral (HPV, EBV, HSV) infections in oral submucous fibrosis and oral cancer from India. Acta Otolaryngol 2010;130:11:1306-1311.

19. Jayasooriya PR, Abeyratne S, Ranasinghe AW, et al. Focal epithelial hyperplasia (Heck's disease): report of two cases with PCR detection of human papillomavirus DNA. Oral Diseases 2004;10:4:240-243.

20. Lübbe J, Kormann A, Adams V, et al. HPV-11- and HPV-16-Associated Oral Verrucous Carcinoma. Dermatology 1996;192: 217-221.

21. Marur S, D'Souza G, Westra W, et al. HPV-associated head and neck cancer: a virus-related cancer epidemic The lancet oncology 2010;11:8:781-789.

22. Miller CS, Johnstone B . Human papillomavirus as a risk factor for oral squamous cell carcinoma: A meta-analysis 1982-1997. Oral Surgery, Oral Medicine, Oral Pathology, Oral Radiology, and Endodontology 2001;91:6:622-635.

23. Cunningham L, Paganob G, Li M, et al. Overexpression of p16INK4 is a reliable marker of human papillomavirus-induced oral high-grade squamous dysplasia. Oral Surgery, Oral Medicine, Oral Pathology, Oral Radiology, and Endodontology 2006;102:1:77-81. 
24. Ritchie JM, Smith E, Summersgi K, et al. Human papillomavirus infection as a prognostic factor in carcinomas of the oral cavity and oropharynx. International Journal of Cancer 2003;104: 3: 336-344.

25. Slots J. Oral viral infections of adults. Periodontology 2000 2009; 49: 60-86.

26. Smith M, Ritchie J, Summersgill K, et al. Age, sexual behavior and human papillomavirus infection in oral cavity and oropharyngeal cancers. -International Journal of Cancer 2004;108: 5:766-772.

27. Syrjänen, S. Human papillomavirus (HPV) in head and neck cancer. Journal of Clinical Virology 2005; 32S: S59-S66.

28. Syrjänen, S. Human papillomavirus infections and oral tumors. Medical Microbiology and Immunology, 2003;192:3:123-128.

29. Krasteva A, Kisselova A, Panov VI et al. Oral lesions pathology (In Bulgarian). Publisher: Ivan Sapundzhiev 2011book.

30. Naghashfar Z, Sawada E, Kutcher M, et al. Identification of genital tract papillomaviruses HPV6 and HPV-16 in warts of the oral cavity. Journal of Medical Virology, December 1985;17: 4:313-324.

31. Prabhat V, LakshmiCh, Sai Madhavi N, et al. Multifocal Epithelial Hyperplasia of Oral Cavity Expressing HPV 16 Gene: A Rare Entity. -Hindawi's Independent Journals. Case Reports in Dentistry 2013; Article ID 871306, 4.

32. Bruni L, DiazM, Castellsagué X, et al. Cervical Human Papillomavirus Prevalence in 5 Continents: Meta-Analysis of 1 Million Women with Normal Cytological Findings J Infect Dis, 2010;15: 202:12:1789-1799.

33. Neville B, Pindborg J, Garlick J, et al. Human Papillomavirus Infection of the Oral Mucosa. merican Journal of Dermatopathology 1991;13:4: 321-430.

34. Nielsen $\mathrm{H}$, Norrild $\mathrm{B}$, Vedtofte $\mathrm{P}$, et al. Human papillomavirus in oral premalignant lesions. European Journal of Cancer Part B: Oral Oncology 1996; 32:e 4,264-270.

35. Niv A, Sion-Vardi N, Gatot A, et al. Identification and typing of human papillomavirus (HPV) in squamous cell carcinoma of the oral cavity and oropharynx. Journal of Laryngology \& Otology 2000;114:01:41-46.

36. Razavi SM, Ghalayani P, SalehiMR, et al. Human papilloma virus as a possible factor in the pathogenesis of oral lichen planus. Dent Res J (Isfahan) 2009;6:2:82-86.

37. Huang F, Li H, Liao C, et al. Association of HPV infections with second primary tumors in earlystaged oral cavity cancer. Oral Dis 2012;8:809-815.

38. Nelke H, Lysenko L, LeszczyszynJ, et al. Human papillomavirus and its influence on head and neck cancer predisposition. Postepy Hig Med Dosw 2013;15:67:610-616.

39. Muñoz N, Bosch F, de Sanjosé S, et al. International Agency for Research on Cancer Multicenter Cervical Cancer Study Group Epidemiologic. Classification of Human Papillomavirus Types Associated with Cervical Cancer. N Engl J Med 2003;348:518.

40. Herrero R, Castellsagué X, Pawlita M, et al. Human Papillomavirus and Oral Cancer: The International Agency for Research on Cancer Multicenter Study .JNCI J Natl Cancer Inst 2003;95:23:1772-1783.

41. Attard A, Praveen, P Dunn P,et al. Epstein-Barr virus - positive mucocutaneous ulcer of the oral cavity: the importance of having a detailed clinical history to reach a correct diagnosis. Oral Surg Oral Med Oral Pathol Oral Radiol 2012;114,2114: e37-e39

42. Kreimer AR, Alberg A, Patti R, et al. Oral Human Papillomavirus Infection in Adults Is Associated with Sexual Behavior and HIV Serostatus. J Infect Dis 2004;189: 4: 686-698.

43. Katiyar S, ThelmaBK, NS Murthy, et al. Polymorphism of the p53 codon 72 Arg/Pro and the risk of HPV type 16/18-associated cervical and oral cancer in India. Mol Cell Biochem 2003; 252(12):117-124. 
44. Lill C, Kornek G, Bachtiary B, et al. Survival of patients with HPV-positive oropharyngeal cancer after radiochemotherapy is significantly enhanced. Wien: Klin Wochenschr 2011;23: 7-8: 215221.

\section{Corresponding author}

Assya Krasteva

asyakrasteva@abv.bg 